\title{
Kerr-lens mode-locked Tm-doped sesquioxide ceramic laser
}

\author{
Yongguang ZhaO, ${ }^{1,2}$ LI Wang, ${ }^{1}$ Weidong Chen, ${ }^{1,3},{ }^{*}$ Pavel Loiko, ${ }^{4}$ \\ Yicheng Wang, ${ }^{1,5}$ Zhongben Pan, $^{6}$ Hanlin Yang, ${ }^{6,7}$ Wei Jing, ${ }^{6}$ Hui Huang, ${ }^{6}$ \\ Jiachen LiU, ${ }^{7}$ Xavier Mateos, ${ }^{8,}$ " Zhengping Wang, ${ }^{9}$ Xinguang XU, ${ }^{9}$ \\ UWe Griebner, ${ }^{1}$ and Valentin Petrov ${ }^{1}$
}

\author{
${ }^{1}$ Max Born Institute for Nonlinear Optics and Short Pulse Spectroscopy, Max-Born-Str. 2a, 12489 Berlin, Germany \\ 2 Jiangsu Key Laboratory of Advanced Laser Materials and Devices, Jiangsu Normal University, Xuzhou 221116, China \\ ${ }^{3}$ Key Laboratory of Optoelectronic Materials Chemistry and Physics, Fujian Institute of Research on the Structure of Matter, Chinese Academy \\ of Sciences, Fuzhou, 350002 Fujian, China \\ ${ }^{4}$ Centre de Recherche sur les lons, les Matériaux et la Photonique (CIMAP), UMR 6252 CEA-CNRS-ENSICAEN, Université de Caen, 6 Boulevard du \\ Maréchal Juin, 14050 Caen Cedex 4, France \\ ${ }^{5}$ Photonics and Ultrafast Laser Science, Ruhr Universität Bochum, Universitätsstraße 150, 44801 Bochum, Germany \\ ${ }^{6}$ Institute of Chemical Materials, China Academy of Engineering Physics, Mianyang 621900, China \\ ${ }^{7}$ Key Laboratory of Advanced Ceramics and Mechanical Technology of Ministry of Education, School of Materials Science and Engineering, \\ Tianjin University, Tianjin 300072, China \\ ${ }^{8}$ Universitat Rovira i Virgili, Física i Cristal-lografia de Materials i Nanomaterials (FiCMA-FiCNA) 43007, Tarragona, Spain. "Serra Húnter Fellow \\ ${ }^{9}$ State Key Laboratory of Crystal Materials and Institute of Crystal Materials, Shandong University, Jinan 250100, China \\ *Corresponding author: Weidong.Chen@mbi-berlin.de
}

Received XX Month XXXX; revised XX Month, XXXX; accepted XX Month XXXX; posted XX Month XXXX (Doc. ID XXXXX); published XX Month XXXX

Kerr-lens mode-locked solid-state laser operation at $\sim 2 \mu \mathrm{m}$ is investigated. Using a $\mathrm{Tm}^{3+}$-doped $(\mathrm{Lu}, \mathrm{Sc})_{2} \mathrm{O}_{3}$ "mixed" sesquioxide ceramic as a gain medium, pulses as short as $58 \mathrm{fs}$ are generated at $\sim 2081 \mathrm{~nm}$ via softaperture Kerr-lens mode-locking. The average output power amounts to $220 \mathrm{~mW}$ at a pulse repetition rate of 84.8 MHz. The emitted spectrum at the long-wavelength wing extends to $>2.2 \mu \mathrm{m}$ which is attributed to vibronic transitions of the $\mathrm{Tm}^{3+}$ ions. The latter is found to be essential for generating pulses with durations in the 50fs range. (C) 2021 Optical Society of America

http://dx.doi.org/10.1364/OL.99.099999

Since the first demonstration of sub-100 fs bulk lasers emitting in the $2 \mu \mathrm{m}$ spectral range in 2017, a Tm: $\mathrm{MgWO}_{4}$ laser mode-locked (ML) by graphene saturable absorber (SA) [1], a remarkable progress has been achieved in this field. Several types of "slow" SAs, such as SEmiconductor Saturable Absorber Mirrors (SESAMs) [2] and single-walled carbon nanotubes (SWCNTs) [3, 4] were applied to start and stabilize the soliton type mode-locking [5]. Pulses as short as $54 \mathrm{fs}$ at $2048 \mathrm{~nm}$ were generated from a SESAM ML $\mathrm{Tm}:\left(\mathrm{Lu}, \mathrm{Y}_{2} \mathrm{O}_{3}\right.$ "mixed" ceramic laser with an average output power of $51 \mathrm{~mW}$ [6]. A slightly longer pulse duration of $57 \mathrm{fs}$ was reported using the same gain material and a SWCNT-SA [7].
Kerr-lens mode-locking (KLM) is another, well-established technique, in particular interesting for the 2- $\mu \mathrm{m}$ spectral range where no commercially available SAs exist. It is based on selffocusing in combination with an intracavity aperture. This creates an intensity dependent quasi-instantaneous self-amplitude modulation which acts as an artificial "fast" SA supporting the generation of extremely short pulses down to few fs $[8,9]$. KLM features: (i) support of broadband operation without the penalty of the non-saturable loss of "slow" SAs [10], and (ii) no operating wavelength limitations inherent to "slow" SAs [11,12].

The challenge of KLM near $2 \mu \mathrm{m}$ as compared to $1-\mu \mathrm{m}$ relates to a great extent to the weaker Kerr effect (lower nonlinear refractive index ( $\left.n_{2}\right)$ for a given laser host material) and the associated higher critical power for self-focusing. Normally, tight focusing in the laser gain medium or an extra Kerr material is required to overcome the above-mentioned limitations. Nevertheless the first KLM laser around $2 \mu \mathrm{m}$ was demonstrated only in 2017 [13-15], 8 years after the first passively ML laser using a "slow" SA [16]. The first sub100-fs KLM Tm laser comprised a Tm: $\mathrm{Sc}_{2} \mathrm{O}_{3}$ crystal pumped by a $1611 \mathrm{~nm}$ fiber amplifier. It delivered 72-fs pulses at $2108 \mathrm{~nm}$ with an average output power of $130 \mathrm{~mW}$ [17]. Subsequently, a "slow" SWCNT-SA-assisted KLM operation was also demonstrated and 76-fs were generated at $2037 \mathrm{~nm}$ from a Tm: $\mathrm{MgWO}_{4}$ laser [18].

Compared to other $\mathrm{Tm}^{3+}$ laser host materials, the cubic sesquioxides $\mathrm{A}_{2} \mathrm{O}_{3}$ (where $\mathrm{A}=\mathrm{Y}, \mathrm{Lu}, \mathrm{Sc}$ or their combination) exhibit a relatively high $n_{2}$ value favoring KLM operation. Their 


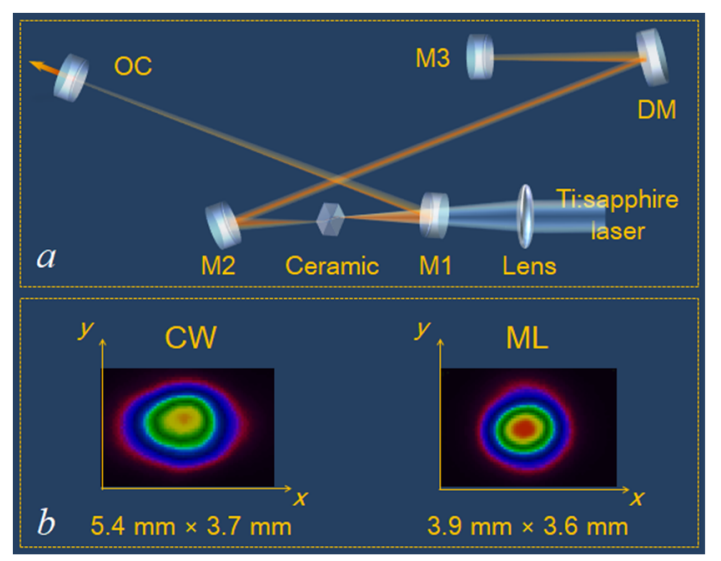

Fig. 1. Schematic of the KLM Tm: $(\mathrm{Lu}, \mathrm{Sc})_{2} \mathrm{O}_{3}$ ceramic laser (a). Output beam profiles in the CW and ML regimes (b). (M1-M2, dichroic mirrors; $\mathrm{DM}$, dispersive mirror; OC, output coupler; CW, continuous wave; $\mathrm{ML}$, mode-locked).

strong crystal field and large ground-state Stark splitting lead to smooth and broad gain profiles supporting emission far beyond $2 \mu \mathrm{m}$, which is exceptional among the $\mathrm{Tm}^{3+}$-doped materials. Furthermore, their attractive thermo-mechanical properties favor high average/peak power ML operation [19].

The technology of transparent polycrystalline ceramics not only relaxes the constraint of high melting temperatures for the sesquioxides, but also offers easier elaboration of "mixed"materials which exhibit compositional disorder leading to additional inhomogeneous broadening of the dopant spectral lines. Here, based on the extremely smooth and broad gain profiles of $\mathrm{Tm}^{3+}$ doped "mixed" lutetia-scandia $(\mathrm{Lu}, \mathrm{Sc})_{2} \mathrm{O}_{3}$ transparent ceramics in conjunction with their relatively large $n_{2}$ value we explore the power scalability of sub-100-fs KLM lasers at $\sim 2 \mu \mathrm{m}$.

Almost pore-free $\mathrm{Tm}:\left(\mathrm{Lu}_{2} / 3 \mathrm{Sc}_{1 / 3}\right)_{2} \mathrm{O}_{3}$ transparent ceramic with a measured $\mathrm{Tm}^{3+}$ doping level of 2.8 at.\% was fabricated by Hot Isostatic Pressing (HIP) of commercial powders at $1800^{\circ} \mathrm{C} / 195 \mathrm{MPa}$ in $\mathrm{Ar}$ atmosphere [20]. KLM laser operation was investigated using a five-mirror linear astigmatically compensated $\mathrm{X}$-shaped cavity. The uncoated ceramic sample with an aperture of $3 \mathrm{~mm} \times 3 \mathrm{~mm}$ and a thickness of $3 \mathrm{~mm}$ was mounted in a watercooled copper holder (coolant temperature: $14^{\circ} \mathrm{C}$ ) and placed at Brewster's angle between two concave dichroic folding mirrors M1 and M2 (RoC $=-100 \mathrm{~mm})$. A $795 \mathrm{~nm}$ narrow-linewidth continuous-wave (CW) Ti:Sapphire laser was used as a pump source. The pump beam was focused into the ceramic sample by a spherical lens $(f=70 \mathrm{~mm})$ resulting in a beam waist radius of $33 \mu \mathrm{m} \times 77 \mu \mathrm{m}$ in the sagittal and tangential planes, respectively. The corresponding cavity waist radius in the CW mode inside the ceramic sample, estimated by the ABCD formalism, was $30 \mu \mathrm{m} \times 57 \mu \mathrm{m}$. The cavity was completed by a flat dispersive mirror (DM), a flat rear mirror (M3), and a plane-wedged output coupler (OC), Fig. 1(a). The roundtrip group delay dispersion (GDD) due to the 3-mm thick ceramic sample amounted to $-200 \mathrm{fs}^{2}$ at $2.08 \mu \mathrm{m}$, estimated by averaging the refractive indices of $\mathrm{Lu}_{2} \mathrm{O}_{3}$ and $\mathrm{Sc}_{2} \mathrm{O}_{3}$ [21]. Taking into account the GDD of the bending DM ( $800 \mathrm{fs}^{2}$ per bounce in the spectral range from 2.0 to $2.2 \mu \mathrm{m}$ ) the total round-trip GDD amounted to $\sim-1850 \mathrm{fs}^{2}$.

The Tm:(Lu,Sc $)_{2} \mathrm{O}_{3}$ ceramic laser was initially characterized in the CW regime with a $0.5 \%$ OC. At an absorbed pump power $\left(P_{\mathrm{abs}}\right)$ of $1.8 \mathrm{~W}$, a maximum CW output power of $490 \mathrm{~mW}$ was achieved
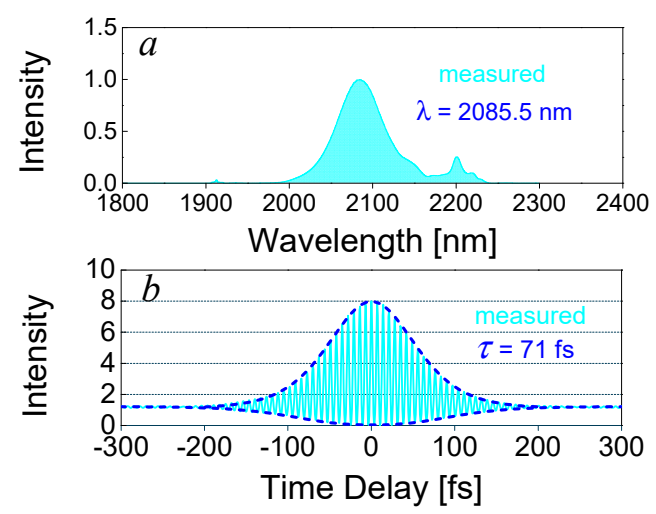

Fig. 2. $\mathrm{KLM} T \mathrm{Tm}:(\mathrm{Lu}, \mathrm{Sc})_{2} \mathrm{O}_{3}$ ceramic laser with $T_{\mathrm{OC}}=0.5 \%$. Optical spectrum (a) and interferometric autocorrelation trace (b).

at $2088.1 \mathrm{~nm}$ with an optical conversion efficiency of $26.8 \%$. KLM operation was established by aligning the resonator towards the edge of the stability region by translating the folding mirror (M2) by several hundreds of micrometers away from the pump mirror (M1) to discriminate the CW regime. KLM was not self-starting. The transition from the CW to the KLM regime was achieved by a slight knock on the flat rear mirror (M3) or the OC. This led to abrupt increase in the average output power from 147 to $247 \mathrm{~mW}$. At $P_{\text {abs }}=1.1 \mathrm{~W}$ the corresponding optical conversion efficiency was $22.5 \%$. Figure 2 shows the recorded optical spectrum and the interferometric autocorrelation trace. The spectrum was centered at $2085.5 \mathrm{~nm}$ with a full width at half maximum (FWHM) of $65 \mathrm{~nm}$, Fig. 2(a). The autocorrelation trace gives a pulse duration of $71 \mathrm{fs}$ by assuming a sech ${ }^{2}$-shaped temporal profile, see Fig. 2(b), which is $22.4 \%$ longer than the Fourier-transform limit. A significant change in the recorded far-field beam profile was observed by placing an infrared camera at $\sim 2 \mathrm{~m}$ from the OC. The shrinking of the far-field beam diameter from $5.4(x) \mathrm{mm} \times 3.7(y) \mathrm{mm}$ to $3.9(x) \mathrm{mm} \times 3.6(y) \mathrm{mm}$, as shown in Fig. 1(b), is a clear evidence for a soft-aperture Kerr-lens effect and self-focusing inside the ceramic sample. The total cavity length was $\sim 1.8 \mathrm{~m}$ resulting in a pulse repetition rate of $\sim 84.8 \mathrm{MHz}$. The peak on-axis laser intensity in the ceramic was estimated to be $\sim 510 \mathrm{GW} / \mathrm{cm}^{2}$.

The pulse duration was further shortened by using a $0.2 \%$ OC while maintaining $P_{\mathrm{abs}}=1.1 \mathrm{~W}$. The average output power dropped to $136 \mathrm{~mW}$, however, the FWHM of the spectrum increased to $70 \mathrm{~nm}$. Scaling of the pump power while maintaining the softaperture KLM regime, was possible up to $P_{\text {abs }}=1.6 \mathrm{~W}$ resulting in an average output power of $220 \mathrm{~mW}$. The optical spectrum was further broadened but exhibited a significant deviation from an ideal sech $^{2}$-shape profile, with three distinct peaks at 2081.4, 2181.5 and $2226.7 \mathrm{~nm}$, see Fig. 3(a). Pulses as short as $58 \mathrm{fs}$ were recorded after external linear chirp compensation with a 3-mm thick $\mathrm{ZnS}$ ceramic plate (GDD $\left.=465 \mathrm{fs}^{2}\right)$. This pulse duration is equivalent to 8 optical cycles which was confirmed by recording the fringe-resolved autocorrelation trace, presented in Fig. 3(b). A long-scale intensity autocorrelation scan (15 ps) is shown in the inset of Fig 3(b), confirming a single pulse ML operation without any pedestals or multi-pulses. The deconvolved pulse duration was $13.7 \%$ above the Fourier-transform limit, see Fig. 3(a). The peak on-axis laser intensity in the ceramic was $\sim 623 \mathrm{GW} / \mathrm{cm}^{2}$. Compared to previous sub-100 fs pulse generation results obtained with Tm-doped mixed sesquioxide ceramics using real SAs $[2,6,7]$, KLM clearly demonstrates average power scalability 


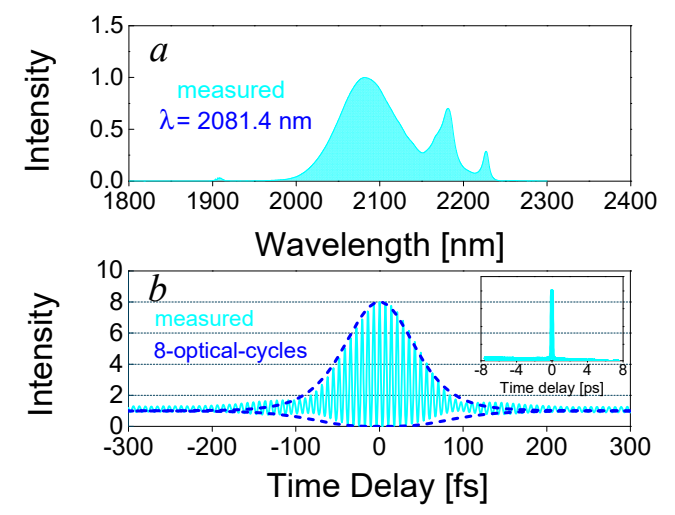

Fig. 3. $\mathrm{KLM} T \mathrm{Tm}:(\mathrm{Lu}, \mathrm{Sc})_{2} \mathrm{O}_{3}$ ceramic laser with $T_{\mathrm{OC}}=0.2 \%$. Optical spectrum (a) and interferometric autocorrelation traces of the shortest pulses (b). Inset in (b): simultaneously measured long-scale ( $\pm 7.5 \mathrm{ps})$ background-free autocorrelation trace.

combined with shortest pulse durations.

The KLM pulse train was characterized by a radio frequency (RF) spectrum analyzer. The recorded fundamental beat note at 84.8 $\mathrm{MHz}$ exhibited a high extinction ratio of $77 \mathrm{dBc}$ above the noise level, see Fig. 4(a). This, together with the uniform harmonic beat notes shown in Fig 4(b) indicates highly stable ML operation without any unwanted Q-switched or multiple pulsing instabilities.

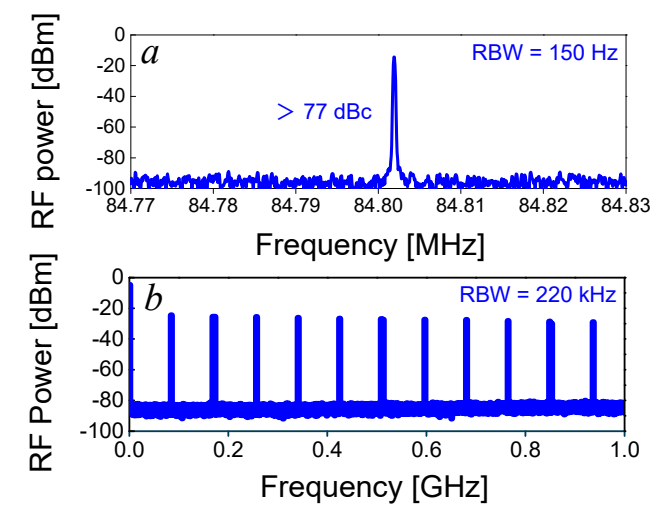

Fig. 4. $\mathrm{RF}$ spectra of the $\mathrm{KLM} \mathrm{Tm}:(\mathrm{Lu}, \mathrm{Sc})_{2} \mathrm{O}_{3}$ ceramic laser: fundamental beat note (a) and 1-GHz span (b). RBW: resolution bandwidth.

For sub-80 fs pulses, the broadband long-wavelength emission extended to $\sim 2.2 \mu \mathrm{m}$, see Fig. 2(a) and Fig. 3(a). Given a strong coupling between the electronic transition of $\mathrm{Tm}^{3+}$ ions and the host material phonons exists, this emission may refer to multiphonon-assisted transitions of the $\mathrm{Tm}^{3+}$ ions [22, 23]. To confirm this hypothesis, we calculated the stimulated emission (SE) cross-section spectrum for the ${ }^{3} \mathrm{~F}_{4} \rightarrow{ }^{3} \mathrm{H}_{6}$ transition of $\mathrm{Tm}^{3+}$ ions in the Tm:(Lu,Sc $)_{2} \mathrm{O}_{3}$ ceramic, see Fig. 5(a). According to the Stark splitting of the ${ }^{3} \mathrm{H}_{6}$ and ${ }^{3} \mathrm{~F}_{4} \mathrm{Tm}^{3+}$ multiplets determined at $10 \mathrm{~K}$, the purely electronic transitions at room temperature (RT) were computed as shown by vertical dashes in Fig. 5(a).

Among them, the longest wavelength is $2099 \mathrm{~nm}$ which corresponds to an electronic transition occurring from the lowest Stark level (sub-level) of the ${ }^{3} \mathrm{~F}_{4}$ multiplet $\left(5683 \mathrm{~cm}^{-1}\right)$ to the highest sub-level of the ${ }^{3} \mathrm{H}_{6}$ multiplet $\left(919 \mathrm{~cm}^{-1}\right)$. The emission at longer wavelengths extending up to $2.3 \mu \mathrm{m}$ has a vibronic nature
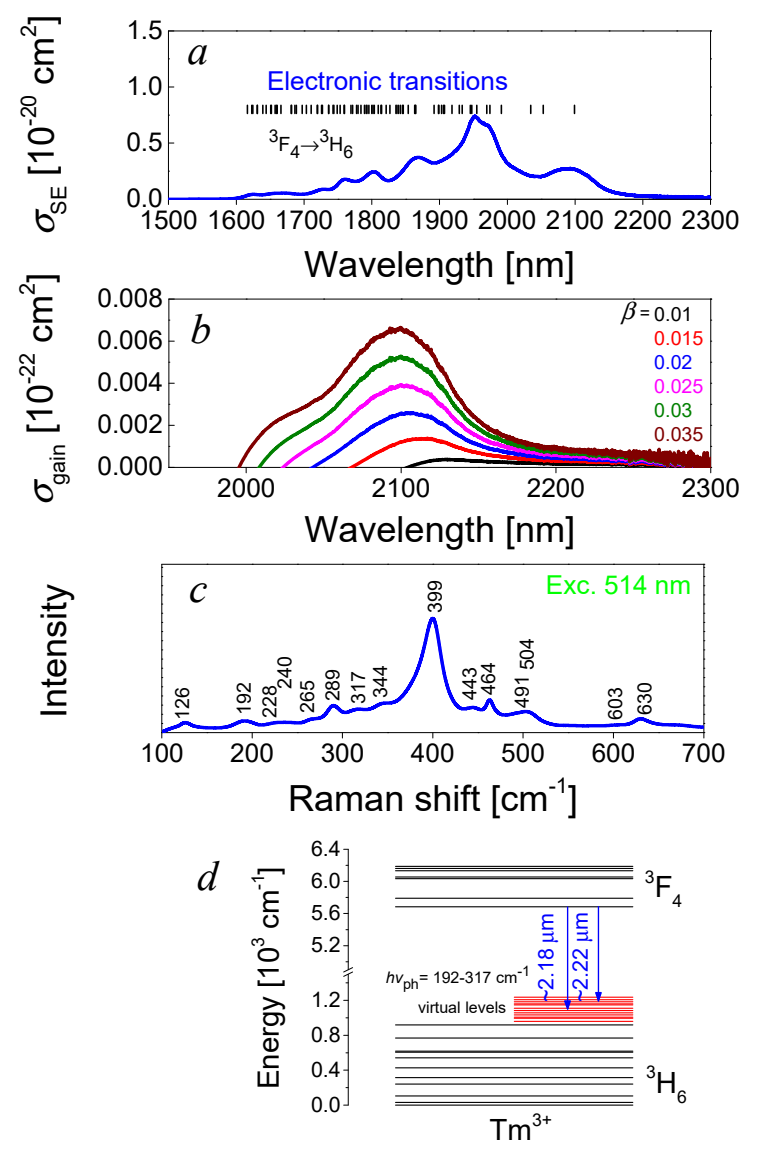

Fig. 5. Spectroscopy of $\mathrm{Tm}:(\mathrm{Lu}, \mathrm{Sc})_{2} \mathrm{O}_{3}$ ceramic: (a) stimulatedemission cross-section, $\sigma_{\mathrm{SE}}$, for the ${ }^{3} \mathrm{~F}_{4} \rightarrow{ }^{3} \mathrm{H}_{6}$ transition, vertical dashes mark all possible wavelengths of purely electronic Stark transitions, (b) calculated gain cross-section, $\sigma_{\text {gain, }}$ spectra for different inversion rates $\beta=N_{2}\left({ }^{3} \mathrm{~F}_{4}\right) / N_{\mathrm{Tm}}$, (c) Raman spectrum, $\lambda_{\mathrm{exc}}=514 \mathrm{~nm}$, numbers denote the peak frequencies in $\mathrm{cm}^{-1}$; (d) Derived crystal-field splitting of ${ }^{3} \mathrm{H}_{6}$ and ${ }^{3} \mathrm{~F}_{4}$ multiplets of $\mathrm{Tm}^{3+}$ ions in $\mathrm{C}_{2}$ sites revealed at $10 \mathrm{~K}$. The red lines illustrate virtual energy-levels due to electron-phonon coupling with the host vibrations participating in laser emission at $\sim 2.1-2.2 \mu \mathrm{m}$.

and it determines to a large extent the gain spectra for small inversion rates $\beta$, see Fig. 5(b). For very small inversion rates (high finesse cavities), e.g., $\beta=0.01$, the gain cross-section spectrum reveals a smooth and broad profile from 2.1 to $2.3 \mu \mathrm{m}$. For slightly higher $\beta$, a local peak at $\sim 2.1 \mu \mathrm{m}$ emerges, spanning from $\sim 2.0$ to $2.3 \mu \mathrm{m}$, in agreement with our observations in the present KLM $\mathrm{Tm}:(\mathrm{Lu}, \mathrm{Sc})_{2} \mathrm{O}_{3}$ ceramic laser, cf. Fig. 2(a) and Fig. 3(a).

The measured Raman spectrum of the Tm: $(\mathrm{Lu}, \mathrm{Sc})_{2} \mathrm{O}_{3}$ ceramic is shown in Fig. 5(c). Apart from the most intense band at $399 \mathrm{~cm}^{-1}$, it reveals multiple bands at lower frequencies, $126-344 \mathrm{~cm}^{-1}$. By adding these vibrations to the higher-lying sub-levels of the ${ }^{3} \mathrm{H}_{6}$ ground state (representing an electron-phonon coupling), we obtain a set of densely located virtual energy levels at 768 $1236 \mathrm{~cm}^{-1}$, as shown in Fig. 5(d). The long-wave emission above $2.1 \mu \mathrm{m}$ can be thus explained by transitions from the upper laser level $\left({ }^{3} \mathrm{~F}_{4}\right)$ to one or several of such virtual levels (lower laser level). Full utilization of the vibronic emission in the present ML laser is impossible mainly due to the reflectivity characteristics of the pump mirror M1 and the OC. They limit the spectrum from the long wave side starting from $\sim 2.2 \mu \mathrm{m}$ and prevent operation in the flat gain region, see Fig. 5(b). The spectral and temporal reshaping 
of the laser output through the OC in particular results in a significant deviation from the ideal $\operatorname{sech}^{2}$-shape spectral profile indicated by structured satellite peaks around $\sim 2.2 \mu \mathrm{m}$, cf. Fig. 2(a) and Fig. 3(a) but also in deviation from the ideal temporal fit, cf. Fig. 3(b). The unmanageable intracavity GDD at the long-wave spectral wing beyond $2.1 \mu \mathrm{m}$ due to the same cavity elements may also contribute to the formation of such satellites, however the gain at such wavelengths is still provided by vibronic emission. The appearance of such spectral sidebands at the long-wave wing was also observed in other ML Tm-doped sesquioxide lasers when the spectral bandwidths exceeded $60 \mathrm{~nm}[2,6,7,17]$. Alternative gain mechanisms at such long wavelengths suggested in [17] include stimulated Raman scattering and the upper lying ${ }^{3} \mathrm{H}_{4} \rightarrow{ }^{3} \mathrm{H}_{5} \mathrm{Tm}^{3+}$ transition but we have no evidence for such effects in our laser.

In conclusion, we have demonstrated a KLM Thulium sesquioxide laser based on a "mixed" Tm: $(\mathrm{Lu}, \mathrm{Sc})_{2} \mathrm{O}_{3}$ transparent ceramic. Using a $0.2 \%$ OC, pulses as short as 58 fs, i.e., 8 optical cycles, were generated at $\sim 2081 \mathrm{~nm}$. The average output power amounted to $220 \mathrm{~mW}$ at a repetition rate of $84.8 \mathrm{MHz}$. Thus, KLM using other Tm-doped broadband gain media (e.g., disordered or composite ones) and/or a proper cavity design is expected to provide yet shorter pulses near $2 \mu \mathrm{m}$, i.e., few optical cycles. The observation of long-wave emission at $\sim 2.2 \mu \mathrm{m}$ within the ML laser spectrum indicates contribution of $\mathrm{Tm}^{3+}$ vibronic transitions. Having in mind that such multiphonon-assisted long wavelength emission can be fully resonated it seems advantageous for further spectral broadening and pulse shortening.

Funding. National Natural Science Foundation of China (52032009, 61975208, 62075090, 51761135115, 61850410533, 52072351); Deutsche Forschungsgemeinschaft (PE 607/14-1); Natural Science Foundation of Jiangsu Province (BK20190104); Sino-German Scientist Cooperation and Exchanges Mobility Programme (M-0040); Foundation of President of China Academy of Engineering Physics (CAEP) (YZJJLX2018005); Fundation of Key Laboratory of Research on Chemistry and Physics of Optoelectronic Materials (CAS 2008DP173016).

Acknowledgment. Y. Zhao acknowledges financial support from the Alexander von Humboldt Foundation through a Humboldt fellowship.

Disclosures. The authors declare no conflicts of interest

Disclosures. Data underlying the results presented in this paper are not publicly available at this time but may be obtained from the authors upon reasonable request.

\section{References}

1. Y. C. Wang, W. D. Chen, M. Mero, L. Z. Zhang, H. F. Lin, Z. B. Lin, G. Zhang, F. Rotermund, Y. J. Cho, P. Loiko, X. Mateos, U. Griebner, and V. Petrov, Opt. Lett. 42, 3076 (2017).

2. Y. Wang, W. Jing, P. Loiko, Y. Zhao, H. Huang, X. Mateos, S. Suomalainen, A. Härkönen, M. Guina, U. Griebner, and V. Petrov, Opt. Express 26, 10299 (2018).

3. Y. Wang, Y. Zhao, Z. Pan, J. E. Bae, S. Y. Choi, F. Rotermund, P. Loiko, J. M. Serres, X. Mateos, H. Yu, H. Zhang, M. Mero, U. Griebner, and V. Petrov, Opt. Lett. 43, 4268 (2018).
4. Z. Pan, Y. Wang, Y. Zhao, H. Yuan, X. Dai, H. Cai, J. E. Bae, S. Y. Choi, F. Rotermund, X. Mateos, J. M. Serres, P. Loiko, U. Griebner, and V. Petrov, Photon. Res. 6, 800 (2018).

5. V. Petrov, Y. Wang, W. Chen, Z. Pan, Y. Zhao, L. Wang, M. Mero, S. Y. Choi, F. Rotermund, W. B. Cho, J. Wei, H. Huang, H. Cai, L. Zhang, Z. Lin, P. Loiko, X. Mateos, X. Xu, J. Xu, H. Yu, H. Zhang, S. Suomalainen, M. Guina, A. Härkönen and U. Griebner, Proc. SPIE 11209, 112094G (2020).

6. Y. Zhao, L. Wang, W. Chen, Z. Pan, Y. Wang, P. Liu, X. Xu, Y. Liu, D. Shen, J. Zhang, M. Guina, X. Mateos, P. Loiko, Z. Wang, X. Xu, J. Xu, M. Mero, U. Griebner, and V. Petrov, Appl. Opt. 59, 10493 (2020).

7. Y. Zhao, L. Wang, Y. Wang, J. Zhang, P. Liu, X. Xu, Y. Liu, D. Shen, J. E. Bae, T. G. Park, F. Rotermund, X. Mateos, P. Loiko, Z. Wang, X. $\mathrm{Xu}$, J. Xu, M. Mero, U. Griebner, V. Petrov, and W. Chen, Opt. Lett. 45, 459 (2020).

8. T. Brabec, C. Spielmann, P. F. Curley, and F. Krausz, Opt. Lett. 17, 1292 (1992).

9. R. Ell, U. Morgner, F. X. Kärtner, J. G. Fujimoto, E. P. Ippen, V. Scheuer, G. Angelow, T. Tschudi, M. J. Lederer, and A. Boiko, Opt. Lett. 26, 373 (2001).

10. O. Pronin, and J. Brons, in High Power Laser Systems (IntechOpen, 2018).

11. S. Ruan, J. M. Sutherland, P. M. W. French, J. R. Taylor, and B. H. T. Chai, Opt. Lett. 20, 1041 (1995).

12. R. Paiella, F. Capasso, C. Gmachl, D. L. Sivco, J. N. Baillargeon, A. L. Hutchinson, A. Y. Cho, and H. C. Liu, Science 290, 1739 (2000).

13. F. Canbaz, I. Yorulmaz, and A. Sennaroglu, Opt. Lett. 42, 3964 (2017).

14. J. Zhang, K. F. Mak, and O. Pronin, IEEE J. Sel. Top. Quantum Electron. 24, 1 (2018).

15. M. Tokurakawa, E. Fujita, and C. Kränkel, Opt. Lett. 42, 3185 (2017).

16. W. B. Cho, A. Schmidt, J. H. Yim, S. Y. Choi, S. Lee, F. Rotermund, U. Griebner, G. Steinmeyer, V. Petrov, X. Mateos, M. C. Pujol, J. J. Carvajal, M. Aguilo, and F. Diaz, Opt. Express 17, 11007 (2009).

17. A. Suzuki, C. Kränkel, and M. Tokurakawa, Appl. Phys. Express 13, 052007 (2020).

18. L. Wang, W. Chen, Y. Zhao, Y. Wang, Z. Pan, H. Lin, G. Zhang, L. Zhang, Z. Lin, and J. Bae, T. G. Park, F. Rotermund, P. Loiko, X. Mateos, M. Mero, U. Griebner and V. Petorv, Opt. Lett. 45, 6142 (2020).

19. C. Kränkel, IEEE J. Sel. Top. Quantum Electron. 21 (2015).

20. W. Jing, P. Loiko, J. M. Serres, Y. Wang, E. Vilejshikova, M. Aguiló, F. Díaz, U. Griebner, H. Huang, V. Petrov, and X. Mateos, Opt. Mater. Express 7, 4192 (2017).

21. D. E. Zelmon, J. M. Northridge, N. D. Haynes, D. Perlov, and K. Petermann, Appl. Opt. 52, 3824 (2013).

22. P. Loiko, Y. C. Wang, J. M. Serres, X. Mateos, M. Aguilo, F. Diaz, L. Z. Zhang, Z. B. Lin, H. F. Lin, G. Zhang, E. Vilejshikova, E. Dunina, A. Kornienko, L. Fomicheva, V. Petrov, U. Griebner, and W. D. Chen, J. Alloy Compd. 763, 581 (2018).

23. P. Loiko, X. Mateos, S. Y. Choi, F. Rotermund, J. M. Serres, M. Aguiló, F. Díaz, K. Yumashev, U. Griebner, and V. Petrov, J. Opt. Soc. Am. B 33, D19 (2016). 


\section{References}

1. Y. C. Wang, W. D. Chen, M. Mero, L. Z. Zhang, H. F. Lin, Z. B. Lin, G. Zhang, F. Rotermund, Y. J. Cho, P. Loiko, X. Mateos, U. Griebner, and V. Petrov, "Sub-100 fs Tm:MgWO 4 laser at 2017 nm mode locked by a graphene saturable absorber," Optics Letters 42, 3076-3079 (2017).

2. Y. Wang, W. Jing, P. Loiko, Y. Zhao, H. Huang, X. Mateos, S. Suomalainen, A. Härkönen, M. Guina, U. Griebner, and V. Petrov, "Sub-10 optical-cycle passively mode-locked $\mathrm{Tm}:\left(\mathrm{Lu}_{2 / 3} \mathrm{Sc}_{1 / 3) 2} \mathrm{O}_{3}\right.$ ceramic laser at $2 \mu \mathrm{m}$," Optics Express 26, 10299-10304 (2018).

3. Y. Wang, Y. Zhao, Z. Pan, J. E. Bae, S. Y. Choi, F. Rotermund, P. Loiko, J. M. Serres, X. Mateos, H. Yu, H. Zhang, M. Mero, U. Griebner, and V. Petrov, "78 fs SWCNT-SA mode-locked Tm:CLNGG disordered garnet crystal laser at $2017 \mathrm{~nm}$," Optics Letters 43, 4268-4271 (2018).

4. Z. Pan, Y. Wang, Y. Zhao, H. Yuan, X. Dai, H. Cai, J. E. Bae, S. Y. Choi, F. Rotermund, X. Mateos, J. M. Serres, P. Loiko, U. Griebner, and V. Petrov, "Generation of 84-fs pulses from a mode-locked Tm:CNNGG disordered garnet crystal laser," Photonics Research 6, 800-804 (2018).

5. V. Petrov, Y. Wang, W. Chen, Z. Pan, Y. Zhao, L. Wang, M. Mero, S. Y. Choi, F. Rotermund, W. B. Cho, W. Jing, H. Huang, H. Yuan, H. Cai, L. Zhang, Z. Lin, P. Loiko, X. Mateos, X. Xu, J. Xu, H. Yu, H. Zhang, S. Suomalainen, M. Guina, A. Härkönen, and U. Griebner, Sub-100-fs bulk solid-state lasers near 2-micron (SPIE, 2019).

6. Y. Zhao, L. Wang, W. Chen, Z. Pan, Y. Wang, P. Liu, X. Xu, Y. Liu, D. Shen, J. Zhang, M. Guina, X. Mateos, P. Loiko, Z. Wang, X. Xu, J. $\mathrm{Xu}, \mathrm{M}$. Mero, U. Griebner, and V. Petrov, "SESAM mode-locked $\mathrm{Tm}: \mathrm{LuYO}_{3}$ ceramic laser generating 54-fs pulses at $2048 \mathrm{~nm}$," Applied Optics 59, 10493-10497 (2020)

7. Y. Zhao, L. Wang, Y. Wang, J. Zhang, P. Liu, X. Xu, Y. Liu, D. Shen, J. E. Bae, T. G. Park, F. Rotermund, X. Mateos, P. Loiko, Z. Wang, X. $\mathrm{Xu}, \mathrm{J} . \mathrm{Xu}, \mathrm{M}$. Mero, U. Griebner, V. Petrov, and W. Chen, "SWCNT-SA mode-locked Tm: $\mathrm{LuYO}_{3}$ ceramic laser delivering 8optical-cycle pulses at $2.05 \mu \mathrm{m}$," Optics Letters 45, 459-462 (2020).

8. T. Brabec, C. Spielmann, P. F. Curley, and F. Krausz, "Kerr lens mode locking," Optics Letters 17, 1292-1294 (1992).

9. R. Ell, U. Morgner, F. X. Kärtner, J. G. Fujimoto, E. P. Ippen, V. Scheuer, G. Angelow, T. Tschudi, M. J. Lederer, and A. Boiko, "Generation of 5-fs pulses and octave-spanning spectra directly from a Ti:sapphire laser," Optics Letters 26, 373-375 (2001).

10. O. Pronin, and J. Brons, "Kerr-Lens Mode-Locked High-Power Thin-Disk Oscillators," in High Power Laser Systems(IntechOpen, 2018).

11. S. Ruan, J. M. Sutherland, P. M. W. French, J. R. Taylor, and B. H. T. Chai, "Kerr-lens mode-locked visible transitions of a Pr:YLF laser," Optics Letters 20, 1041-1043 (1995).

12. R. Paiella, F. Capasso, C. Gmachl, D. L. Sivco, J. N. Baillargeon, A. L. Hutchinson, A. Y. Cho, and H. C. Liu, "Self-mode-locking of quantum cascade lasers with giant ultrafast optical nonlinearities," Science 290, 1739-1742 (2000).

13. F. Canbaz, I. Yorulmaz, and A. Sennaroglu, "Kerr-lens modelocked 2.3- $\mu \mathrm{m} \mathrm{Tm}^{3+}$ :YLF laser as a source of femtosecond pulses in the mid-infrared," Optics Letters 42, 3964-3967 (2017).

14. J. Zhang, K. F. Mak, and O. Pronin, "Kerr-Lens Mode-Locked 2$\mu \mathrm{m}$ Thin-Disk Lasers " IEEE Journal Selected Topic in Quantum Electronics 24, 1-11 (2018).

15. M. Tokurakawa, E. Fujita, and C. Kränkel, "Kerr-lens modelocked $\mathrm{Tm}^{3+}: \mathrm{Sc}_{2} \mathrm{O}_{3}$ single-crystal laser in-band pumped by an Er:Yb fiber MOPA at 1611 nm," Optics Letters 42, 3185-3188 (2017).
16. W. B. Cho, A. Schmidt, J. H. Yim, S. Y. Choi, S. Lee, F. Rotermund, U. Griebner, G. Steinmeyer, V. Petrov, X. Mateos, M. C. Pujol, J. J. Carvajal, M. Aguilo, and F. Diaz, "Passive mode-locking of a Tmdoped bulk laser near $2 \mu \mathrm{m}$ using a carbon nanotube saturable absorber," Optics Express 17, 11007-11012 (2009).

17. A. Suzuki, C. Kränkel, and M. Tokurakawa, "High quality-factor Kerr-lens mode-locked $\mathrm{Tm}: \mathrm{Sc}_{2} \mathrm{O}_{3}$ single crystal laser with anomalous spectral broadening," Applied Physics Express 13, 052007 (2020).

18. L. Wang, W. Chen, Y. Zhao, Y. Wang, Z. Pan, H. Lin, G. Zhang, L. Zhang, Z. Lin, and J. Bae, T. G. Park, F. Rotermund, P. Loiko, X. Mateos, M. Mero, U. Griebner and V. Petorv, "Single-walled carbon-nanotube saturable absorber assisted Kerr-lens modelocked Tm:MgWO 4 laser," Optics Letters 45, 6142-6145 (2020).

19. C. Kränkel, "Rare-Earth-Doped Sesquioxides for Diode-Pumped High-Power Lasers in the 1-, 2-, and 3- $\mu \mathrm{m}$ Spectral Range," IEEE Journal of Selected Topic in Quantum Electronics 21 (2015).

20. W. Jing, P. Loiko, J. M. Serres, Y. Wang, E. Vilejshikova, M. Aguiló, F. Díaz, U. Griebner, H. Huang, V. Petrov, and X. Mateos, "Synthesis, spectroscopy, and efficient laser operation of "mixed" sesquioxide Tm:(Lu,Sc)2O3 transparent ceramics," Optical Materials Express 7, 4192-4202 (2017).

21. D. E. Zelmon, J. M. Northridge, N. D. Haynes, D. Perlov, and K. Petermann, "Temperature-dependent Sellmeier equations for rare-earth sesquioxides," Applied Optics 52, 3824-3828 (2013).

22. P. Loiko, Y. C. Wang, J. M. Serres, X. Mateos, M. Aguilo, F. Diaz, L. Z. Zhang, Z. B. Lin, H. F. Lin, G. Zhang, E. Vilejshikova, E. Dunina, A. Kornienko, L. Fomicheva, V. Petrov, U. Griebner, and W. D. Chen, "Monoclinic Tm: $\mathrm{MgWO}_{4}$ crystal: Crystal-field analysis, tunable and vibronic laser demonstration," Journal of Alloys and Compounds 763, 581-591 (2018).

23. P. Loiko, X. Mateos, S. Y. Choi, F. Rotermund, J. M. Serres, M. Aguiló, F. Díaz, K. Yumashev, U. Griebner, and V. Petrov, "Vibronic thulium laser at $2131 \mathrm{~nm}$ Q-switched by single-walled carbon nanotubes," Journal of the Optical Society of America B 33, D19-D27 (2016). 